QUEIROGA, R.C.F.; BEZERRA NETO, F.; NEGREIROS, M.Z.; OLIVEIRA, A.P.; AZEVEDO, C.M.S.B. Produção de alface em função de cultivares e tipos de tela de sombreamento nas condições de Mossoró. Horticultura Brasileira, Brasília, v. 19, n. 3, p. 192-196, novembro 2.001.

\title{
Produção de alface em função de cultivares e tipos de tela de sombreamento nas condições de Mossoró.
}

\author{
Roberto Cleiton F. Queiroga ${ }^{1}$; Francisco Bezerra Neto ${ }^{1}$; Maria Zuleide Negreiros ${ }^{1}$; Ademar P. Oliveira ${ }^{2}$; \\ Celicina Maria Silveira Borges Azevedo ${ }^{1}$ \\ ${ }^{1}$ ESAM, C. Postal 137, 59.625-970 Mossoró - RN; ${ }^{2}$ UFPB, C. Postal 02, .58.397-000 Areia - PB; Email:robertocleiton@hotmail.com
}

\begin{abstract}
RESUMO
Conduziram-se dois experimentos na horta do Departamento de Fitotecnia da ESAM, no período de outubro de 1999 a janeiro de 2000. O objetivo do primeiro experimento foi avaliar o desempenho de três cultivares de alface sombreadas por três tipos de tela e o do segundo, comparar a produtividade da alface sob os três tipos de tela de sombreamento com a do cultivo a céu aberto. O delineamento experimental utilizado, em ambos os experimentos, foi de blocos casualizados completos. No primeiro experimento, os tratamentos resultaram de um fatorial $3 \times 3$, provenientes da combinação dos três tipos de tela de sombreamento (branca e verde, com malha de 2 x $2 \mathrm{~mm}$, e preta com malha irregular) e três cultivares de alface (Great Lakes, Verônica e Regina), com quatro repetições. No segundo experimento, os tratamentos provieram dos três tipos de tela de sombreamento e do cultivo da alface, cultivar Verônica a céu aberto, com três repetições. O espaçamento utilizado em ambos os experimentos foi de $0,20 \times 0,20 \mathrm{~m}$. As características avaliadas foram altura e diâmetro de plantas, número de folhas por planta, massa seca da parte aérea, produtividade, taxa de crescimento relativo, ganho de produtividade, rendas bruta e líquida e taxa de retorno. A altura de plantas foi afetada pela interação tipos de tela de sombreamento e cultivares. $\mathrm{O}$ diâmetro de planta e o número de folhas por planta foram influenciados apenas pelas cultivares. O teor de massa seca e a produtividade foram influenciados pelos tipos de tela de sombreamento e cultivares. A utilização de tela de cor branca associada com a cultivar Great Lakes na fase de muda constituiuse em melhor taxa de retorno por Real investido, e numa tecnologia para incrementar a rentabilidade do produtor na região semi-árida do Nordeste brasileiro.
\end{abstract}

\begin{abstract}
Performance of lettuce cultivars under different shading intensity and types of polyethylene net in Mossoró.

Two experiments were carried out in the Escola Superior de Agricultura de Mossoró, in Brazil. The first experiment, from October to November 1999, evaluated the performance of three lettuce cultivars grown at the nursery stage under shading and three types of polyethylene net, and the second experiment, from December 1999 to January 2000, compared the lettuce yield under shading and no shading. The experimental design in both experiments was a randomized complete block. Treatments in the first experiment were factorial combinations of three types of polyethylene net $(2 \times 2 \mathrm{~mm}$ white and green nets and half-shade black net) and three lettuce cultivars (Great Lakes, Verônica and Regina) replicated four times. Treatments in the second experiment were these three types of polyethylene net plus one where lettuce cultivar Verônica was grown under no shading (control) replicated three times. The lettuce spacing in both experiments was $0.20 \times 0.20 \mathrm{~m}$. The performance of lettuce was evaluated through plant height and diameter, leaf number per plant, shoot dry matter content, yield, relative growth rate, gross and net incomes and rate of return. Shading and cultivar interaction affected plant height. Plant diameter and leaf number per plant were affected only by cultivars. Shoot dry matter content and yield were affected by shading as well as cultivars. White polyethylene net shading associated with lettuce cultivar Great Lakes provided the highest economic indices when compared to no shading.
\end{abstract}

Palavras-chave: Lactuca sativa, produção de mudas, indicadores econômicos.

Keywords: Lactuca sativa, production of seedlings, polyethylene net.

\section{(Aceito para publicação em 10 de outubro de 2.001)}

\begin{abstract}
A alface é uma hortaliça folhosa bastante consumida em todo o mundo. Devido à sua condição de perecibilidade e de baixa resistência ao transporte é produzida próximo aos grandes centros consumidores (Vidigal et al., 1995). Proveniente de clima temperado cuja adaptação a locais de temperatura e luminosidade elevadas tem gerado obstáculos no seu crescimento impedindo que ela expresse todo seu potencial genético (Setúbal \& Silva, 1992). No Nordeste brasileiro, o cultivo desta hortaliça restringe-se a peque-
\end{abstract}

nas áreas, com a utilização de cultivares pouco adaptadas às condições climáticas da região, concorrendo para o florescimento precoce e baixa produtividade. No Estado do Rio Grande do Norte a produção de alface é baixa quando comparada com outras regiões do país, não atendendo com isso a sua demanda interna. Os métodos de produção existentes são rudimentares, não correspondendo às expectativas de produções esperadas. Dentre os fatores que estão associados a estes baixos rendimentos, destacam-se a falta de assistên- cia técnica e a falta de difusão de tecnologias que melhorem o manejo cultural desta olerícola.

Minami (1993), afirma que a produção de mudas em olerícolas tem sido considerada uma atividade normal e obrigatória para a maioria das culturas. Contudo, as mudas vêm sendo produzidas de formas diversas, e a tendência atual é sofisticar ainda mais, sempre procurando aprimorar a qualidade com a introdução de novas técnicas.

Telas de prolipropileno (sombrite) vêm sendo cada vez mais utilizadas, re- 
duzindo a incidência direta dos raios solares nas espécies que necessitam menor fluxo de energia radiante. Ramos (1995) trabalhando com alface, verificou que o sombreamento proporcionou maior altura de plantas e maior produção de massa seca, tanto na fase de formação de mudas quanto na fase de campo. A maior produtividade foi observada em mudas sombreadas, com a cultivar Great Lakes destacando-se das demais.

Em trabalho desenvolvido por Silva (1999), utilizando tela de nylon de cor preta, com malha de $2 \times 2 \mathrm{~mm}$ e colocada a $25 \mathrm{~cm}$ de altura do leito da sementeira, em três cultivares de alface e seis espaçamentos, em Mossoró (RN), concluiu-se que a produtividade e a produção de massa seca total foi maior quando as plantas foram sombreadas apenas na fase de sementeira.

$\mathrm{O}$ uso de telas de sombreamento e de cultivares adequadas às condições de temperatura e luminosidade elevadas na produção de mudas de alface pode contribuir para diminuir os efeitos extremos da radiação, resultando em mudas vigorosas, de boa qualidade para transplante e, conseqüentemente, aumento na produtividade e na qualidade das folhas para consumo (Silva,1999).

O objetivo deste trabalho foi avaliar o desempenho de três cultivares de alface sombreadas por três tipos de tela na fase de muda, em condições de temperatura e luminosidade elevadas.

\section{MATERIAL E MÉTODOS}

Dois experimentos foram conduzidos na horta do Departamento de Fitotecnia da Escola Superior de Agricultura de Mossoró, sendo o primeiro no período de outubro a novembro de 1999 e o segundo no período de dezembro de 1999 a janeiro de 2000, em solo classificado como Podzólico VermelhoAmarelo Equivalente Eutrófico, Grande Grupo Eutrustalfs do "Soil Taxonomy". O município de Mossoró está situado a $5^{\circ} 11$ ' de latitude Sul e $37^{\circ} 20^{\prime}$ de longitude Oeste e altitude de $18 \mathrm{~m}$. O clima da região, segundo Thornthwaite, é semi-árido e de acordo com Köeppen é BSwh', seco e muito quente, com duas estações climáticas: uma seca, que vai geralmente de junho a janeiro, e uma chuvosa, de fevereiro a maio (Carmo Filho \& Oliveira, 1989).

O delineamento experimental utilizado em ambos experimentos foi o de blocos casualizados completos. No primeiro experimento, os tratamentos originaram-se de um fatorial $3 \times 3$ proveniente da combinação de três tipos de tela de sombreamento (branca e verde, com malha de 2 × $2 \mathrm{~mm}$ e preta com malha irregular) e três cultivares de alface (Great Lakes, Verônica e Regina) com quatro repetições cada. No segundo, os tratamentos provieram dos mesmos três tipos de tela de sombreamento e do cultivo da alface a céu aberto, com três repetições. Apenas a cultivar Verônica foi utilizada neste ensaio. As parcelas foram constituídas de 25 plantas, com uma área total de $1,0 \mathrm{~m}^{2} \mathrm{e}$ área útil de $0,36 \mathrm{~m}^{2}$. Este último experimento, foi conduzido com o intuito de avaliar a performance dos três tipos de tela de sombreamento em relação ao cultivo da alface em céu aberto (tratamento testemunha).

Na fase de produção de mudas foram utilizados copos descartáveis com formato de cone invertido, com $8,0 \mathrm{~cm}$ de diâmetro superior, $5,5 \mathrm{~cm}$ de diâmetro inferior e $13,0 \mathrm{~cm}$ de altura, apresentando um volume de $372,0 \mathrm{~cm}^{3}$, distribuídos uniformemente em canteiros no sentido leste-oeste. O substrato utilizado foi uma mistura de húmus e vermiculita na proporção de $2: 1$, isento de pragas e doenças, sendo, portanto, indicado para produção de mudas de hortaliças.

No primeiro experimento, a semeadura foi realizada no dia 4 de outubro de 1999, sendo colocadas 4 a 5 sementes no centro de cada recipiente a aproximadamente $0,4 \mathrm{~cm}$ de profundidade. No segundo, a semeadura foi realizada no dia 5 de dezembro de 1999. Logo após a semeadura os recipientes foram colocadas sob tela de nylon, de cores branca, verde e preta, sendo todas colocadas a $50 \mathrm{~cm}$ de altura do leito da sementeira. A altura da tela de sombreamento foi utilizada segundo recomendação de Rocha (2000). O sombreamento foi empregado logo após a semeadura, permanecendo até a véspera do transplante das mudas.

Aos sete dias após a emergência foi realizado o desbaste, deixando-se uma planta por recipiente, e aos quinze dias, foi efetuada uma adubação foliar com a formulação $14 \% \mathrm{~N} ; 4 \% \mathrm{P}_{2} \mathrm{O}_{5}, 6 \% \mathrm{~K}_{2} \mathrm{O}$; 0,8\% S; $1,5 \% \mathrm{Mg} ; 2 \% \mathrm{Zn} ; 1,5 \% \mathrm{Mn}$; $0,1 \%$ B e $0,05 \%$ Mo, na base de $30 \mathrm{~g} / 20$ litros de água.

A cultura da alface foi estabelecida por transplante direto em canteiros, medindo cada um 12,0 m de comprimento, 1,20 m de largura e 0,20 $\mathrm{m}$ de altura, distanciados $0,5 \mathrm{~m}$ uns dos outros. O espaçamento utilizado foi 0,20 x $0,20 \mathrm{~m}$. Na adubação de plantio foram incorporados $80 \mathrm{t} / \mathrm{ha}$ de esterco bovino bem curtido. Em ambos os experimentos, o transplantio foi realizado 22 dias após semeadura, quando as mudas apresentavam de quatro a seis folhas definitivas.

Diariamente, foram efetuadas irrigações por micro aspersão, uma pela manhã e duas à tarde, de forma a manter o teor de água no solo próximo à capacidade de campo. Foram realizadas três capinas manuais, visando à manutenção da cultura sempre no limpo. Fez-se necessário a aplicação do produto Imidracop para o controle da mosca branca. A adubação nitrogenada foi realizada uma semana após o transplantio, utilizando-se $20 \mathrm{~g} / \mathrm{m}^{2}$ de sulfato de amônio. Uma semana após, foi realizada a adubação foliar com a formulação $14 \% \mathrm{~N} ; 4 \% \mathrm{P}_{2} \mathrm{O}_{5} ; 6 \% \mathrm{~K}_{2} \mathrm{O} ; 0,8 \% \mathrm{~S}$; $1,5 \% \mathrm{Mg} ; 2 \% \mathrm{Zn} ; 1,5 \% \mathrm{Mn} ; 0,1 \% \mathrm{~B} \mathrm{e}$ $0,05 \%$ Mo, à base de $30 \mathrm{~g} / 20$ litros de água, sendo repetida na terceira semana, em ambos os experimentos.

No primeiro experimento, a colheita foi realizada no dia 22 de novembro de 1999 e no segundo no dia 24 de janeiro de 2000, sendo ambos colhidos com 50 dias da semeadura.

No primeiro experimento avaliaramse a altura e diâmetro de plantas (expressa em $\mathrm{cm}$ ), número de folhas por planta, massa seca da parte aérea e produtividade ( $\mathrm{t} / \mathrm{ha})$, taxa de crescimento relativo $\left(\mathrm{TCR}=1_{\mathrm{n}} \mathrm{W}_{2-} 1_{\mathrm{n}} \mathrm{W}_{1} / \mathrm{t}_{2}-\mathrm{t}_{1}\right.$, onde $1_{\mathrm{n}}$ é o logaritmo neperiano e $\mathrm{W}_{2}$ é a massa seca de plantas na época da colheita $t_{2}$ e $W_{1}$ é a massa seca de plantas na época do transplante $\mathrm{t}_{1}$ ), expressa em g. $100 \mathrm{~g}^{-1} \cdot \mathrm{dia}^{-1}$, e a análise econômica (rendas bruta e líquida e taxa de retorno).

A análise econômica do emprego das telas e das cultivares foi realizada pelo 
Tabela 1. Altura e diâmetro de plantas, número de folhas/planta, massa seca da parte aérea, produtividade, taxa de crescimento relativo de alface sob sombreamento. Mossoró, ESAM, 1999.

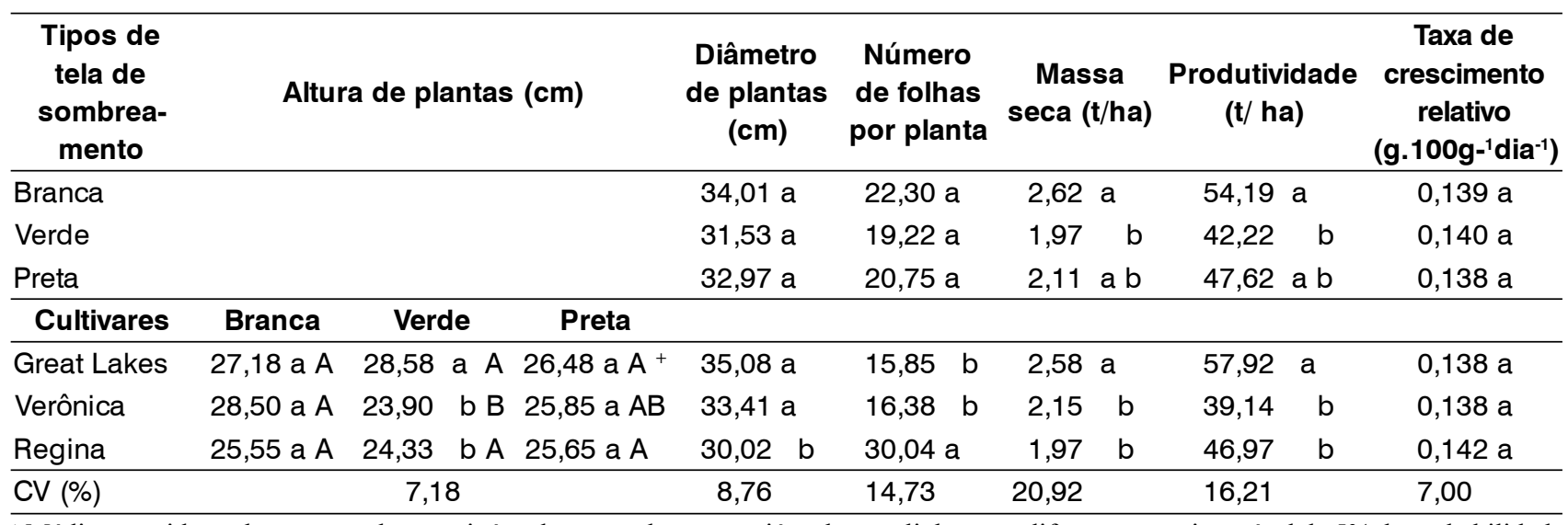

${ }^{+}$Médias seguidas pelas mesmas letras minúsculas nas colunas e maiúsculas nas linhas não diferem entre si no nível de 5\% de probabilidade pelo teste de Tukey.

custo e receita da produção e respectiva taxa de retorno, conforme procedimentos empregados por Pereira et al. (1985). A renda bruta foi obtida multiplicandose a produtividade de cada tratamento pelo valor do produto obtido, que foi de $\mathrm{R} \$ 0,50 / \mathrm{kg}$, pago ao produtor no mês de janeiro de 2000, independente do tamanho e do tipo da alface. A renda líquida foi calculada subtraindo-se da renda bruta, os custos operacionais de produção, provenientes de insumos mais serviços. Estes custos foram calculados para cada tratamento baseados nos coeficientes de custo de insumos e serviços utilizados em um hectare de alface em nível experimental. Foram considerados os preços de insumos e serviços vigentes no mês de janeiro de 2000, na cidade de Mossoró. A taxa de retorno por Real investido em cada tratamento, foi obtida por meio da relação entre a renda bruta e o custo de produção de cada tratamento.

No segundo experimento, avaliouse o ganho de produtividade de alface sob telas de sombreamento, em relação ao cultivo a céu aberto (sem uso de telas), sendo expresso em porcentagem. As análises de variância para as características avaliadas foram efetuadas em programa SPSS/PC (Norusis, 1990). Para a comparação das médias, usou-se o teste de Tukey no nível de $5 \%$ de probabilidade (Pimentel Gomes, 1990).

\section{RESULTADOS E DISCUSSÃO}

Foi observado efeito significativo da interação tipos de tela de sombreamento versus cultivares na altura de plantas de alface. No desdobramento da interação observou-se efeito das cultivares apenas sob a tela de cor verde, com a cultivar Great Lakes registrando maior altura de plantas, embora não diferindo estatisticamente das cultivares Verônica e Regina sob as telas branca e preta (Tabela 1). Esta maior altura das plantas de alface da cultivar Great Lakes observada sob a tela de cor verde se deve, provavelmente, à menor incidência da radiação solar nas plantas, diminuindo assim a temperatura e favorecendo o crescimento em altura das plantas. Ramos (1995) reporta que a orientação dos cloroplastos em direção à luz em condições de baixa luminosidade permite absorção máxima. Por outro lado, o desdobramento dos tipos de tela de sombreamento dentro de cada cultivar revelou que as telas diferiram apenas dentro da cultivar Verônica, com a tela de cor branca registrando maiores alturas de plantas.

Observou-se também efeito significativo apenas de cultivares sobre o diâmetro de plantas de alface. Maiores diâmetros foram registrados nas cultivares Great Lakes e Verônica (Tabela 1). Mesmo em condições de temperatura e luminosidade elevadas ocorreu entrelaçamento das folhas em todos os tratamentos, o que permite afirmar que o sombreamento ocorrido nas bordas das folhas provavelmente diminuiu a área fotossinteticamente ativa, influenciando assim na expansão máxima das folhas de alface. Estes resultados concordam com os de Silva (1999), onde a cultivar Great Lakes se destacou das cultivares Elisa e Babá de Verão, em relação ao diâmetro das plantas.

Em relação ao número de folhas por planta ocorreu também efeito significativo apenas de cultivares, tendo a cultivar Regina destacado-se das demais com relação a esta característica (Tabela 1). Este resultado concorda em parte com o obtido por Porto (1999), onde a cultivar Regina destacou-se das cultivares Great Lakes e Tainá quanto ao número de folhas por planta. Estas diferenças observadas para tal característica são devidas, provavelmente, à carga genética de cada cultivar.

Foram observados efeitos significativos de tipos de tela de sombreamento e de cultivares sobre a massa seca da parte aérea e produtividade. Os maiores teores de massa seca e produtividade foram registrados sob a tela branca, 2,62 $\mathrm{t} / \mathrm{ha}$ e $54,19 \mathrm{t} / \mathrm{ha}$, embora não tenham diferido estatisticamente dos resultados obtidos sob a tela de cor preta (Tabela 1). Resultados semelhantes para a produtividade de alface, cultivar Verônica, foram obtidos no segundo experimento, onde a tela de cor branca sobressaiuse das demais, com a produtividade de $62,96 \mathrm{t} / \mathrm{ha}$, embora também não tenha diferido da tela de cor preta (Tabela 3). Este resultado com a tela de cor branca se deve, provavelmente, à melhor condição de temperatura e luminosidade na fase de muda e confirma, em parte, os obtidos por Edmond et al. (1967), ao afirmarem que quando uma cultura está 
Produção de alface em função de cultivares e tipos de tela de sombreamento nas condições de Mossoró.

Tabela 2. Indicadores econômicos para a produção de alface em função de cultivares e tipos de tela de sombreamento. Mossoró, ESAM, 2000.

\begin{tabular}{|c|c|c|c|c|c|c|c|c|c|}
\hline \multirow{2}{*}{$\begin{array}{c}\text { Cultivares / Tipos de tela } \\
\text { Itens }\end{array}$} & \multicolumn{3}{|c|}{ Great Lakes } & \multicolumn{3}{|c|}{ Verônica } & \multicolumn{3}{|c|}{ Regina } \\
\hline & Branca & Verde & Preta & Branca & Verde & Preta & Branca & Verde & Preta \\
\hline Produção $(\mathrm{t} / \mathrm{ha})=\mathrm{A}$ & 63,26 & 49,72 & 60,76 & 50,90 & 34,72 & 38,74 & 48,40 & 42,22 & 47,27 \\
\hline Valor do produto $(\mathrm{R} \$ / \mathrm{kg})=\mathrm{B}$ & 0,50 & 0,50 & 0,50 & 0,50 & 0,50 & 0,50 & 0,50 & 0,50 & 0,50 \\
\hline $\begin{array}{l}\text { Renda bruta }(\mathrm{R} \$ / \mathrm{ha}) \\
=\mathrm{C}=\mathrm{A} \times \mathrm{B}\end{array}$ & 31630,00 & 24860,00 & 30380,00 & 25450,00 & 17360,00 & 19370,00 & 24200,00 & 21110,00 & 23640,00 \\
\hline Custo da tela $(\mathrm{R} \$ / \mathrm{ha})=\mathrm{D}$ & 1944,00 & 1944,00 & 1944,00 & 1944,00 & 1944,00 & 1944,00 & 1944,00 & 1944,00 & 1944,00 \\
\hline $\begin{array}{l}\text { Custo operacional }(\mathrm{R} \$ / \mathrm{ha}) \\
=\mathrm{E}\end{array}$ & 14767,07 & 14767,07 & 14767,07 & 14767,07 & 14767,07 & 14767,07 & 14767,07 & 14767,07 & 14767,07 \\
\hline Custo total $=F=D+E$ & 16711,07 & 16711,07 & 16711,07 & 16711,07 & 16711,07 & 16711,07 & 16711,07 & 16711,07 & 16711,07 \\
\hline $\begin{array}{l}\text { Renda líquida }(\mathrm{R} \$ / \mathrm{ha}) \\
=\mathrm{G}=\mathrm{C}-\mathrm{F}\end{array}$ & 14918,93 & 8148,93 & 13668,93 & 8738,93 & 648,93 & 2658,93 & 7488,93 & 4398,93 & 6928,93 \\
\hline $\begin{array}{l}\text { Taxa de retorno }(\mathrm{R} \$ / \mathrm{ha}) \\
=\mathrm{H}=\mathrm{C} / \mathrm{F}\end{array}$ & 1,88 & 1,49 & 1,82 & 1,52 & 1,04 & 1,16 & 1,45 & 1,26 & 1,41 \\
\hline
\end{tabular}

Tabela 3. Produtividade de alface, cultivar Verônica, e ganho de produtividade em função dos tipos de tela de sombreamento. ESAM, Mossoró, 2000.

\begin{tabular}{lcr}
\hline \multicolumn{1}{c}{ Tipos de tela de sombreamento } & Produtividade (t/ha) & Ganho de produtividade (\%) \\
\hline Branca & 62,96 a & 27,3 \\
Verde & 52,87 b c & 6,9 \\
Preta & 60,09 a b & 21,5 \\
Testemunha (sem o uso da tela) & $49,44 \quad$ c & - \\
\hline CV (\%) & 6,14 & - \\
\hline
\end{tabular}

sendo conduzida dentro de uma variação ótima de luminosidade, com outros fatores favoráveis, a fotossíntese é elevada e a quantidade de carboidratos utilizados para o crescimento e desenvolvimento da planta é alta.

Sentelhas et al. (1998) avaliando tipos de cobertura na atenuação da radiação solar e luminosidade utilizando tela de cor branca, verde e preta, verificaram que a tela de cor branca apresentou menor irradiação solar global $(26,6 \%)$ e menor luminosidade $(25,1 \%)$ quando comparada, por exemplo, com a tela de cor preta que, apresentou maiores valores de irradiação solar global $(55,4 \%) \mathrm{e}$ luminosidade $(52,3 \%)$. Este fato justifica o uso de tela branca nas condições estudadas, por proporcionar às plantas maiores produtividades.

A cultivar Great Lakes foi a que apresentou maior quantidade de massa seca, $(2,58 \mathrm{t} / \mathrm{ha})$ e produtividade $(57,92$ t/ha) em relação às outras cultivares avaliadas (Tabela 1). Esta produtividade superou a média da região de Mossoró que é de $11 \mathrm{t} / \mathrm{ha}$, a qual se deve, dentre outros fatores, ao emprego de cultivares pouco adaptadas a temperatura e luminosidade elevadas, como também à não-adoção de práticas que minimizam os efeitos extremos da temperatura e luminosidade locais (Ramos, 1995). A superioridade da cultivar Great Lakes em relação a Verônica e Regina se deve à sua resistência às condições de temperatura e luminosidade do semi-árido nordestino.

Não se observou efeito significativo de tipos de tela de sombreamento e de cultivares sobre a taxa de crescimento relativo de plantas (Tabela 1). Isto implica que as diferenças registradas nas outras características observadas se deve às condições de crescimento das plantas de alface na fase de mudas sob as telas e às potencialidades de cada cultivar.

Pelos resultados dos indicadores econômicos, evidenciam-se vantagens nos tipos de tela de sombreamento e cultivares utilizadas. Maiores rendas bruta e líquida e taxa de retorno foram obtidas para a cultivar Great Lakes cultivada sob a tela de cor branca (Tabela 2). Estes resultados corroboram em parte os de Silva (1999), com a cultivar Great Lakes, que destacou-se em relação às cultivares Elisa e Babá de Verão para os índices avaliados.

Maior ganho de produtividade de alface foi obtido da relação tela branca $(27,3 \%)$ com o tratamento da alface a céu aberto (Tabela 3 ). Estes dados corroboram aqueles obtidos por Rocha (2000), que obteve ganho de produtividade de $25,5 \%$ quando cultivou a Great Lakes sob tela de cor branca.

De modo geral, os resultados obtidos evidenciaram que os efeitos da temperatura e luminosidade elevadas podem ser minimizados de forma significativa, quando se utiliza, por exemplo, tela de sombreamento. A tela de cor branca associada a cultivar Great Lakes foi a que proporcionou melhor resultado. A utilização de telas na fase de mudas, constitui-se em um meio de incrementar a rentabilidade do produtor nas condições do semi-árido Nordestino.

\section{LITERATURA CITADA}

CARMO FILHO, F.; OLIVEIRA, O.F. Mossoró: um município do semi-árido nordestino. Características climáticas e aspectos florísticos. Mossoró, ESAM, 1989. 62 p. (Col. Mossoroense B, 672). 
EDMOND, J.B.; SENN, T.L.; ANDREWS, F.S. Principios de horticultura. Mexico: Continental, 1967. p. 119-134.

MINAMI, K. Produção de mudas em recipientes. Piracicaba: ESALQ, 1993. 16 p.

NORUSIS, M.J. SPSSPC Advance Statistics 4.0, Illinois: SPSS Inc., 1990. 315 p.

PEREIRA, E.B.; CARDOSO, A.A.A.; VIEIRA C.; LURES, E.G.; KUGIRARI, Y. Viabilidade econômica do composto orgânico na cultura do feijão. Cariacica - ES: EMCAPA, junho, 1985. 4 p. (Comunicado técnico).

PIMENTEL GOMES. F. Curso de Estatística Experimental, Piracicaba:ESALQ, 8 ${ }^{\mathrm{a}}$ edição, 1990. $430 \mathrm{p}$

PORTO, V.C.N. Cultivares de alface em sistema solteiro e consorciado com cenoura sob temperatura e luminosidade elevadas. Mossoró: ESAM, 1999. 44 p. (Dissertação mestrado).
RAMOS, J.E.L. Sombreamento e tipos de recipientes na formação de mudas e produção em alface. Mossoró, ESAM, 1995. 53 p. (Dissertação mestrado).

ROCHA, R.C.C. Tipos e alturas de sombrites na produção de alface sob temperatura $e$ luminosidade elevadas. Mossoró:ESAM, 2000.73 p. (Mimeografado)

SENTELHAS, P.C.; VILLA NOVA, N.A.; ANGELOCCI, L.R. Efeito de diferentes tipos de cobertura, em mini-estufas, na atenuação da radiação solar e da luminosidade. Revista Brasileira de Agrometeorologia, Piracicaba-SP, v. 6, n. 1, p. 479-481, 1998.
SETÚBAL, W.J.; SILVA, A R. Avaliação do comportamento de alface de verão em condições de calor no município de Teresina - PI. Teresina, UFPI, 1992. 17 p. (Mimeografado).

SILVA, V.F.. Cultivares de alface em diferentes espaçamentos sob temperatura e luminosidade elevadas. Mossoró, ESAM, 1999. 25 p. (Dissertação mestrado).

VIDIGAL, S.M.; RIBEIRO, A.C.; CASALI, V.W.D.; FONTES, L.E.F. Resposta da alface (Lactuca sativa L.).II - Ensaio de casa de vegetação. Revista Ceres, Viçosa-MG, v. 42, n. 239, p. 89-97, 1995. 